\title{
John Toland, Le christianisme sans mystères
}

\section{Peter Balatz}

\section{(2) OpenEdition}

\section{Journals}

\section{Édition électronique}

URL : https://journals.openedition.org/studifrancesi/45867

DOI : 10.4000/studifrancesi.45867

ISSN : 2427-5856

\section{Éditeur}

Rosenberg \& Sellier

\section{Édition imprimée}

Date de publication : 1 octobre 2007

Pagination : 446

ISSN : 0039-2944

\section{Référence électronique}

Peter Balatz, « John Toland, Le christianisme sans mystères », Studi Francesi [En ligne], 152 (LI | II) |

2007, mis en ligne le 30 novembre 2015, consulté le 24 novembre 2021. URL : http://

journals.openedition.org/studifrancesi/45867 ; DOI : https://doi.org/10.4000/studifrancesi.45867

Ce document a été généré automatiquement le 24 novembre 2021.

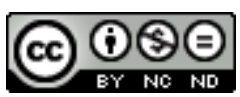

Studi Francesi è distribuita con Licenza Creative Commons Attribuzione - Non commerciale - Non opere derivate 4.0 Internazionale. 


\title{
John Toland, Le christianisme sans mystères
}

\author{
Peter Balatz
}

\section{RÉFÉRENCE}

JOHN TOLAND, Le christianisme sans mystères, édition, introduction et notes par Tristan DAGRON, Paris, Honoré Champion, 2005 («Libre pensée et Littérature clandestine», 23), pp. 270.

1 La traduction éditée ici est celle d'un manuscrit anonyme de la bibliothèque d'Helsinki, fondée sur l'édition de 1702. Le Christianisme sans mystères est un texte difficile à classer. L'intention avouée de son auteur est de défendre la religion chrétienne contre le zèle et la bigoterie d'un clergé qui l'a défigurée. Pourtant, la plupart des interprétations ultérieures ont souligné le caractère subversif et hétérodoxe de cet ouvrage d'inspiration lockéenne dont l'objectif principal est de prouver «qu'il n'y a rien dans l'Evangile qui soit ou contraire à la raison ou au-dessus d'elle et qu'aucun dogme chrétien ne se peut proprement appeler mystère». Dans son avant-propos et son introduction, Tristan Dagron s'efforce de montrer que le livre de Toland (paru en 1696) est très loin d'etre un livre anti-religieux, ni même déiste. L'anticléricalisme ouvert qui le caractérise n'est que la radicalisation de la méfiance que la Réforme nourissait depuis toujours à l'égard de l'institution cléricale. Il ne s'agit donc pas d'une critique rationaliste de la foi (Toland ne veut pas faire de la philosophie «l'interprète de l'Écriture»), mais plutôt d'une exégèse scripturaire parallèle à celles menées par les arminiens (notamment parie fameuxLeClerc). Pour Dagron, l'intérêt principal du texte de Toland réside dans le fait qu'en radicalisant les idées de Locke (exprimées dans l'Essai sur l'entendement humain) et des arminiens, le Christianisme sans mystères détruit le compromis entre la raison et la foi qui avait donné naissance à toute sorte de théologies rationnelles (notamment au "christianisme raisonnable» si cher à Locke). Dans une sorte d'analyse comparée, Dagron prouve que Toland, loin de falsifier ou de gauchir la pensée de son illustre prédécesseur, ne fait que la prolonger et développer dans un sens 
qui, il est vrai, ne rencontre pas l'assentiment de Locke (celui-ci publiera son Reasonableness of Christianity afin de prendre ses distances avec l'irlandais trop audacieux). Par la suite, Dagron procède à la présentation de diverses solutions (celles de Courcelles, de Louis Meyer, de Le Clerc, de Papin et de Malebranche) qui visent toutes la réconciliation de la foi et de la raison, de la théologie et de la philosophie afin de montrer le contexte, mais aussi l'originalité des efforts de Toland. Ces efforts consistent à définir avec une précision linguistique le contenu de la révélation et à prouver que tous les hommes sont capables de la connaître à condition de disposer de la liberté d'examen. Pour Dagron, il serait inutile de chercher dans ce texte les traces du «panthéisme à venir» de son auteur: Toland n'abandonnera ces préoccupations sociniennes et arminiennes que plus tard, dans les Lettres à Serena, d'inspiration néospinoziste. On ne doit pas négliger non plus l'aspect politique, également fondamental de l'ouvrage en question: la publication du Christianisme sans mystères s'inscrit dans un programme républicain visant à sauvegarder l'Angleterre du danger jacobite et à défendre la tolérance religieuse contre toute sorte d'appropriation cléricale du message de l'Evangile. 